\title{
Local Treatment of Spasmodic Torticollis with Botulinum Toxin
}

\author{
Joseph K.C. Tsui, Robin D. Fross, Susan Calne and Donald B. Calne
}

\begin{abstract}
Fifty-six patients with spasmodic torticollis were treated with local injections of botulinum toxin. The drop out rate was $21 \%$. The remaining 44 patients were followed for a period of 3 to 21 months. Thirty-two patients $(76 \%)$ had pain relief out of 42 presenting with pain; $37(66 \%)$ improved in the amount of sustained movements of torticollis. The efficacy was reproducible after repeated injections.
\end{abstract}

RÉSUMÉ: Traitement local du torticollis spasmodique au moyen de la toxine botulique. Nous avons traité 56 patients souffrant de torticollis spasmodique par des injections locales de toxine botulique. Le taux d'abandon en cours de traitement a été de $21 \%$. Les 44 patients restants ont été suivis pendant une période de 3 à 21 mois. Trente-deux patients sur 42 soit $76 \%$ ont éprouvé un soulagement de la douleur; 37 patients, soit $66 \%$ ont amélioré la quantité de mouvements soutenus du torticollis. L'efficacité était reproductible après plusieurs injections.

Can. J. Neurol. Sci. 1987; 14:533-535

There is not yet any curative treatment for dystonia. Results of medical therapy are unpredictable,' local treatment may offer symptomatic relief, particularly for focal dystonias. In the past, injections of quinine and novocaine were tried in spasmodic torticollis. ${ }^{2}$ Though immediate benefit in a few patients was reported, ${ }^{3}$ no long term results were available. The pain and sterile abscesses resulting from these injections limited their clinical application.

Local injection of botulinum-A toxin has been shown to be safe and effective in weakening extraocular muscles in various ophthalmological conditions. ${ }^{4,5,6}$ This technique is potentially useful in focal dystonia if an isolated muscle or group of muscles can be identified as the cause of deformity or disability. This treatment was first established in blepharospasm. ${ }^{7}$ It can be theoretically applied to most other forms of focal dystonia, such as spasmodic torticollis, ${ }^{8.9}$ oromandibular dytonia, dystonic dysphonia, and writer's cramp. ${ }^{10.11}$ It may also be applicable to patients with generalized dystonia where definable groups of muscles are producing localized pain, deformity, or loss of function.

We have treated 56 patients with spasmodic torticollis with local injections of botulinum-A toxin. The results of the initial 21 month follow-up are presented here.

\section{Patients}

The 56 patients with spasmodic torticollis included 23 males and 33 females, with ages ranging from 22 to 72 years (mean $45 \pm 14$ SD). Duration of illness varied from 3 months to 25 years (mean 6.9 \pm 5.5 ). They were followed for a minimum of 3 months and a maximum of 21 months (mean $10 \pm 5.7$ ). Three patients had generalized dystonia, 2 had blepharospasm and oromandibular dystonia, and 2 had writer's cramp associated with the torticollis. The remaining 49 patients had isolated torticollis.

\section{METHODS}

Each patient was given local injections of botulinum-A toxin into two muscles during each treatment session. The dose was $50-70$ mouse units ( 20 to $28 \mathrm{ng}$ ) per muscle, diluted in saline to a concentration of 100 units per $\mathrm{ml}$. The muscles injected were selected (a) according to the clinical observation of the head position and, (b) according to polygraphic surface EMG recordings. The target muscles usually consisted of three superficial pairs of neck muscles, namely, the trapezius, sternomastoid, and splenius capitis muscles (Figure 1). Each patient was instructed to return to the clinic when the effects from the last injection were beginning to wear off. This usually occurred after a period of 2 to 4 months.

The patients were videotaped before and after each treatment and the order of the tapes was randomized. They were assessed by a physician who was "blind". A clinical scoring protocol (Table 1) which had minimal interobserver variability" was employed for the assessment.

Pain was scaled according to the severity (nil, mild, moderate, or severe, scores $0,1,2,3$ respectively). The scores before and after treatment were compared.

Side effects were recorded.

From the Division of Neurology, Department of Medicine, University of British Columbia, Acute Care Unit, Health Sciences Centre Hospital, Vancouver Reprint requests to: Dr. J. Tsui, Division of Neurology, Department of Medicine, University of British Columbia, 2211 Wesbrook Mall, Health Sciences Centre Hospital, Vancouver, B.C., Canada V6T IW5 


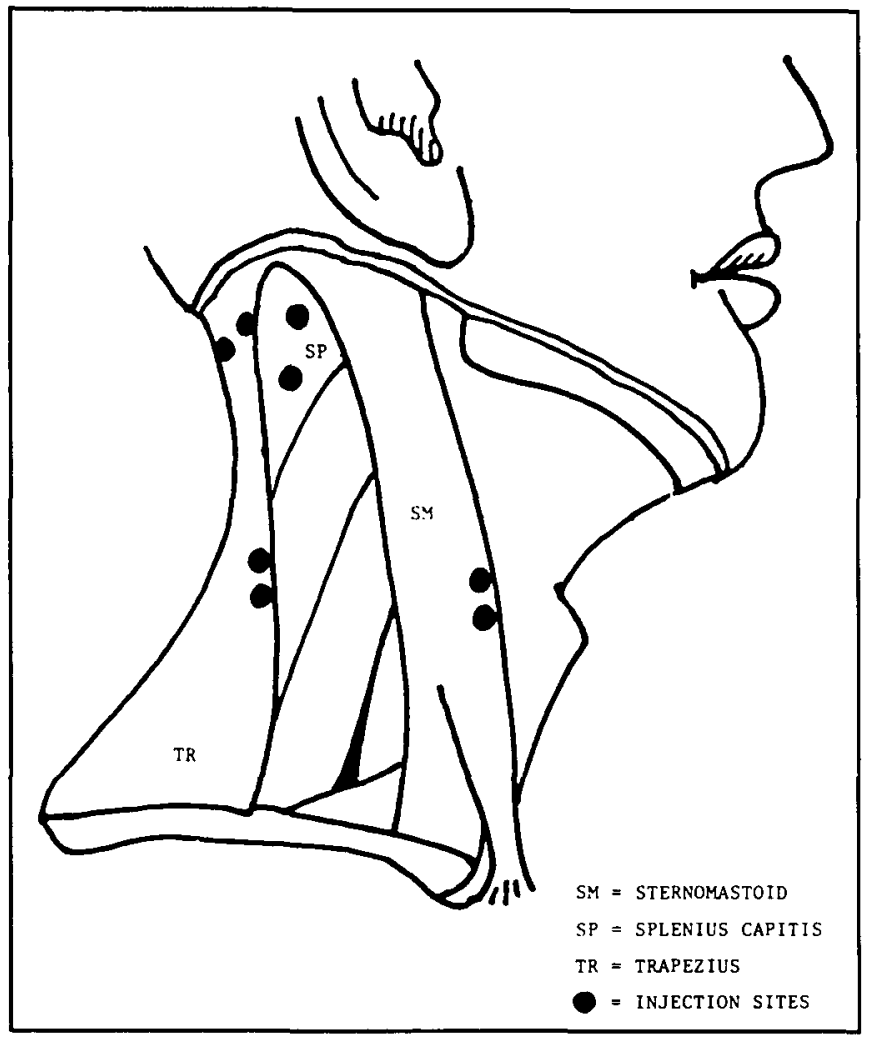

Figure 1 - Site used for injection of botulinum toxin.

\section{RESULTS}

Twelve patients (21\%) found the botulinum toxin ineffective after one or two injections and dropped out of the study within three months.

In the remaining 44 patients, the duration of follow up ranged from 3 to 21 months $(10 \pm 5.7)$. The mean dosage per treatment was $109.8( \pm 26.4)$ mouse units. The time period between each treatment ranged from 4 to 44 weeks (mean 11.6 \pm 5 ).

Sustained movements improved in 37 patients $(66 \%)$ (Figure 2 ). Twenty-four patients $(43 \%)$ had reduction of intermittent neck movements. The mean torticollis score was decreased from $11 \pm 4.6$ to $6 \pm 4.0(p<0.01)$.

Forty-two of the 56 patients had pain associated with spasm of neck muscles. Thirty-two patients $(76 \%)$ reported pain relief

\section{Table 1: Objective scale for rating torticollis}

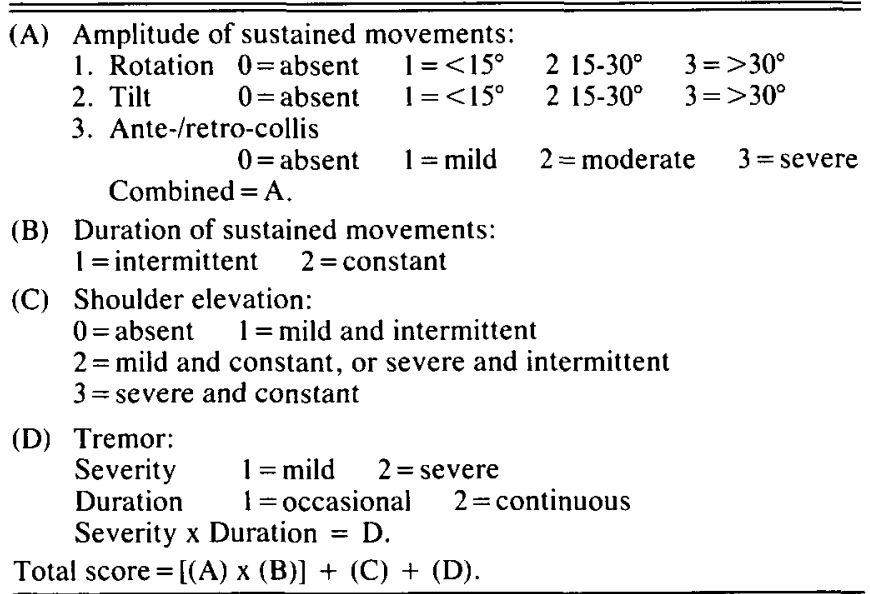

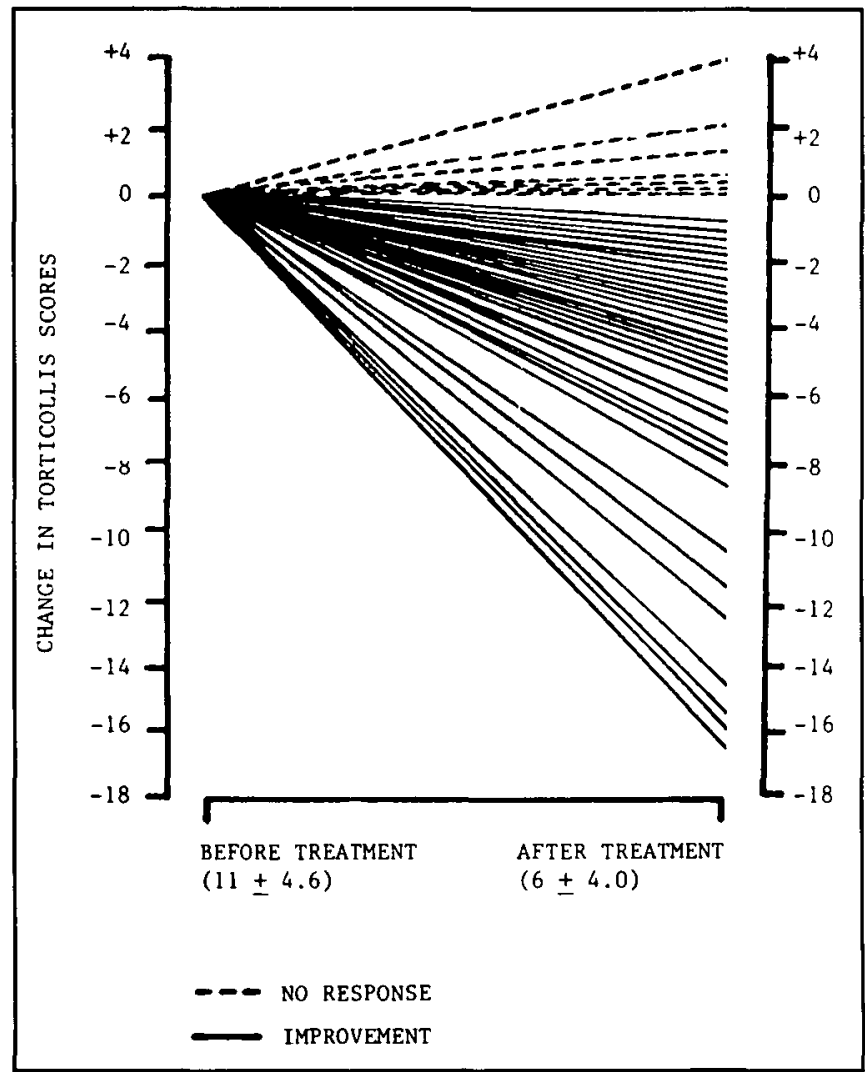

Figure 2 - Change in objective scores in 44 patients.

(Figure 3). Pain scores fell from $2.1 \pm 1.1$ to $0.9 \pm 0.9(p<0.001)$. Excluding those patients who withdrew from the study in the first three months, there were 44 subjects. These can be divided into two groups, one with duration of follow up less than 10 months, and the other more than 11 months. In the first group, 20 out of 24 patients $(83 \%)$ responded, and in the second, 17 out of $20(85 \%)$. The mean fall in the torticollis scores, mean dose required per treatment, and mean duration of effects in the two groups were similar. These are summarized in Table 2.

\section{Side Effects}

Seventeen patients reported transient side effects, each occurring after one of the multiple injections. None recurred during subsequent visits. These problems are listed in Table 3.

\section{Discussion}

These results suggest that the beneficial effects of botulinum toxin in torticollis continue after repeated injections. The benefit following a single treatment lasted for an average of 3 months. The average dose required per treatment was approximately 110 mouse units (44 $\mathrm{ng}$ ).

In each of the 16 patients who reported side effects, the reactions did not recur when the injections were continued. Lassitude and sleepiness were noted in 8 patients, but as stated in our previous double-blind study, ${ }^{9}$ similar symptoms were also commonly reported after injection with a placebo.

One patient had a generalized skin rash 5 days after the injection, but she had a concurrent febrile illness. The relation between the rash and the botulinum toxin was uncertain. 


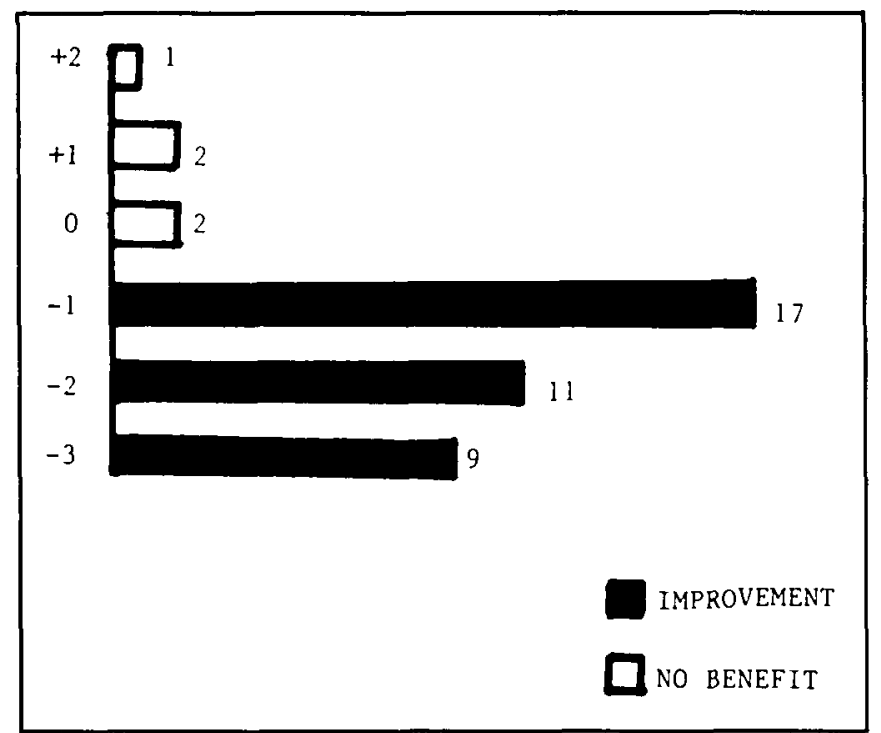

Figure $3-$ Pain relief in 42 patients.

Dysphagia was reported in one patient. It was mild and consisted of occasional choking particularly on lying down. The patient had received botulinum toxin injections to her orbicularis oculi for associated blepharospasm on the same day that her neck was treated. The nature of this side effect was unclear but it could have been a manifestation of early botulism. The total dose during that visit was 150 units ( 100 units for the neck and 50 units for the eyes). Since the average dose of 110 units was adequate for most patients, it is probably not advisable to exceed this.

\section{Conclusion}

Botulinum-A toxin remains effective in spasmodic torticollis after repeated injections and follow up to 21 months. It is a safe form of treatment with few side effects. An average dose of 55 mouse units ( $22 \mathrm{ng}$ ) per muscle is adequate to produce significant reduction of muscle spasm for approximately 3 months.

\section{ACKNOWLEDGEMENT}

This study was supported by the Dystonia Medical Research Foundation.
Table 2:

\begin{tabular}{lcc}
\hline \hline Duration of follow up & 3-10 months & 11-21 months \\
\hline Mean fall in scores & $5.3 \pm 4.6^{*}$ & $4.7 \pm 5.3$ \\
Mean dose/treatment (units) & $111.7 \pm 23$ & $107.4 \pm 30$ \\
Mean duration (weeks) & $11.6 \pm 3.8$ & $12.1 \pm 6.3$ \\
\hline
\end{tabular}

* standard deviation

\section{Table 3:}

Lassitude (transient)

Sleepiness (1 day)

Neck stiffness (1 day)

Neck weakness ( 2 days)

Neck weakness + pain over injection site (I day)

Pain over site of injection ( 1 day)

Neck and back pain ( 2 days)

Tremor increased

Tremor increased + back pain + lassitude (2 days)

Nausea ( 1 day)

Mild dysphagia ( 1 week)

Skin rash 5 days after third injection

\section{REFERENCES}

1. Lal S. Pathophysiology and pharmacotherapy of spasmodic torticollis: a review. Can J Sci Neurol 1979: 6: 427-435.

2. Schaltenbrand G. Klinik und behandlung des Torticollis spasticus. Dtsch Z Nervenheilk 1938: 145: 36-53.

3. Schwind VF. Schutz E. Beitrag zur knoservativen Behandlung des Torticollis spasticus. Der Nervenartz 1960: 31: 318-319.

4. Scott AB, Rosenbaum AL. Collins CC. Pharmacologic weakening of extraocular muscles. Invest Ophthalmol 1973: 12: 924-927.

5. Scott $\mathrm{AB}$. Botulinum toxin injection of eye muscles to correct strabismus. Trans Am Ophthal Soc 1981: 799: 764-770.

6. Scott AB, Kraft SP. Botulinum toxin injection in the management of lateral rectus paresis. Ophthalmology 1985: 95: 676-683.

7. Frueh BR, Felt DP, Wojno TH, et al. Treatment of blepharospasm with botulinum toxin. Arch Ophthalmol 1984: 102: 1464-1468.

8. Tsui JK, Eisen A, Mak J, et al. A pilot study on the use of botulinum toxin in spasmodic torticollis. Can J Neurol Sci 1985 ; 12: 314-316

9. Tsui JK, Eisen A. Stoessl AJ. et al. Double-blind study of botulinum toxin in spasmodic torticollis. The Lancet 1986: 2: 245-247.

10. Brin M, Fahn S, Moskowitz CB. et al. Injections of botulinum toxin for the treatment of focal dystonia. Neurology 1986: 36 (Suppl 1): 120.

11. Jankovic J, Orman J. Botulinum toxin for cranial-cervical dystonia: a double-blind controlled study. Neurology 1986: 36 (Suppl I): 120-121. 